\title{
Development of research capacities in space weather: a successful international cooperation
}

\author{
Christine Amory-Mazaudier ${ }^{1,2, *}$, Sandro Radicella ${ }^{2}$, Patricia Doherty ${ }^{3}$, Sharafat Gadimova ${ }^{4}$, \\ Rolland Fleury ${ }^{5}$, Bruno Nava ${ }^{2}$, Emran Anas ${ }^{6}$, Monique Petitdidier ${ }^{7}$, Yenca Migoya-Orué ${ }^{2}$, \\ Katy Alazo-Cuartas ${ }^{2}$, and Kazuo Shiokawa ${ }^{8}$ \\ ${ }^{1}$ LPP, CNRS/Ecole Polytechnique/Sorbonne Université/Université Paris-Sud/Observatoire de Paris, 75006 Paris, France \\ 2 The Abdus Salam International Centre for Theoretical Physics (ICTP), Strada Costiera 11, 34151 Trieste, Italy \\ ${ }^{3}$ Institute for Scientific Research (ISR), Boston College, Chestnut Hill, 02467 MA, USA \\ ${ }^{4}$ United Nations Office for Outer Space Affairs, 1220 Vienna, Austria \\ ${ }^{5}$ Lab-STICC, UMR 6285, Institut Mines-Telecom Atlantique, Site de Brest, 29238 Brest Cedex 3, France \\ ${ }^{6}$ CRASTE-LF, 10090 Rabat, Morocco \\ ${ }^{7}$ Université Versailles Saint-Quentin, CNRS/INSU, LATMOS, IPSL, 78280 Guyancourt, France \\ ${ }^{8}$ Institute for Space-Earth Environmental Research (ISEE), Nagoya University, 464-8601 Nagoya, Japan
}

Received 17 November 2020 / Accepted 1 February 2021

\begin{abstract}
This paper presents an international cooperation which has successfully developed research capacities in the scientific disciplines of sun-earth relations and space weather in many countries over the world during the past decades. This success was based on the deployment of scientific instruments in countries that did not have them, on the sharing of knowledge and research tools, on thesis supervision and on the integration of researchers trained in their country. This article will only focus on aspects of training conducted by ICTP, Boston College, ICG, SCOSTEP and GIRGEA. We will highlight what has been enhanced in international cooperation to achieve this success and what remains to be done.
\end{abstract}

Keywords: capacity building in space weather in Africa / equatorial geophysics / Global Navigation Satellite System

\section{Chinese Proverb:}

If you want to go fast, go alone

If you want to go far, go together.

\section{Introduction}

The United Nations Basic Space Science Initiative (BSSI), from 1991 to 2012, was aimed at developing astronomy and space science through regional and international cooperation on a worldwide basis. Four major international scientific projects marked three stages in international cooperation in space sciences.

\section{Basic Space Science, BSS (1991-2004)}

A series of workshops on basic space science addressed the status of astronomy in Asia and the Pacific, Latin America and the Caribbean, Africa, and Western Asia. From the results of the deliberations at the workshops, a "Tripod" model for the accelerated implementation of BSS associated activities in developing countries was developed. The Tripod concept was to assure the availability of research tools at a level where the national socio-economical infrastructure would maintain functionality in the university/research laboratory environment, like a small telescope facility; teaching materials introduced in middle and higher education; and application materials for research in BSS such as observing programmes for variable stars.

Different scientific projects were developed in the framework of UN BSS.

\footnotetext{
*Corresponding author: christine. amory@lpp.polytechnique.fr
}

\section{JSWSC}

10 years anniversary issue 


\section{International Equatorial Electrojet Year, IEEY (1992-1994)}

The planetary studies of Earth's environment are limited by the fact that observations at low latitudes and in the southern hemisphere are scarce. At the IAGA General Assembly held in 1981 at Edinburg Keith Cole established the Inter Divisional Commission for developing Countries (ICDC) and proposed the project of the International Equatorial Year. This project was adopted by ICDC on the occasion of the IAGA General Assembly held in 1987 in Vancouver.

This first project introduced space sciences in many countries around the equator and in the southern hemisphere (Amory-Mazaudier et al., 1993; special issue of Brazilian journal of Geophysics, Vo1. 11, 1993).

\section{International Heliophysical Year, IHY, (2005-2009)}

This second project, within the framework of Heliophysics, developed links between the physics of the sun and the terrestrial environment and made it possible to develop a comprehensive teaching of the relations between Sun and Earth. Numerous networks of inexpensive instruments (e.g. GPS and magnetometers) have made it possible to acquire data in countries where there was lack of useful data for space sciences (Harrison et al., 2005; Kitamura et al., 2006; Davila et al., 2007).

\section{International Space Weather Initiative, ISWI, (2010-2012), http://www.iswi-secretariat.org}

The International Space Weather Initiative (ISWI), established in 2009, has its roots in the successful International Heliophysical Year 2007.

ISWI has proved to provide a framework for collaboration among teams of scientists, serving as an example of remarkable international work in instrument operation, data collection and analysis and the publication of scientific results. ISWI has established a platform for a bottom-up approach in order to produce space weather-literate communities, in particular in developing countries, work together as a network for sharing ideas, information and data, and develop joint projects (Haubold \& Gadimova, 2010).

To date, ISWI continues to expand and deploy new and existing instrument arrays. There are currently 19 worldwide instrument arrays with close to 1045 deployments recording data on solar-terrestrial interaction, from coronal mass ejections to variations in the total electron content in the ionosphere. Detailed information on various networks can be found on the ISWI website (http://www.iswi-secretariat.org). Instruments are provided to hosting institutions by entities in Armenia, Brazil, France, Germany, Israel, Japan, Switzerland and the United States of America. In general, the lead scientist or principal investigator of an ISWI project provides the instrumentation and data. The host country provides the human resources, facilities and operational support for the operation of the instrument project, typically at a local university. Host scientists become part of the science team, and all data and data analysis results are shared within the team and made accessible to all users.

This third project developed the discipline of space weather which links the physics of Sun-Earth relationships to the daily life applications.
A fourth project, within the framework of Electronic Geophysical Year (eGY) (2007-2008), eGY-Africa (2007-2008), transverses especially to those space science projects, started in 2007 it was a bottom-up bootstrap effort by scientists from Africa and elsewhere to achieve better internet and Grid Access in universities and similar research and education institutions in Africa (http://www.egy.org/).

All the information on the instruments deployed during the different scientific projects is on the site http://www.iswi-secretariat.org. In section "Projects" all the instruments installed as well as the way to access data and the police concerning the data are listed. All the institutions and universities that have participated in the various projects can be found on the http://www. iswi-secretariat.org site in the "National coordinators" section.

\section{GIRGEA}

\subsection{Projects IEEY, IHY and ISWI}

It was in 1987 in Vancouver during the IAGA conference when the project International Equatorial Electrojet Year (IEEY) was defined. The president of the IAGA was a French researcher, Roger Gendrin. He played a decisive role in the involvement of France in this project by creating a national committee to define the participation of France to IEEY. In fact, during the years 1970-1980, some studies on the ionosphere had been carried out by French researchers in West Africa (with the help of the two existing ionosondes of Dakar and Ouagadougou), but no African scientist had been trained in this field. With regard to the Equatorial Electrojet, studies had been made under the direction of PN Mayaud and a Nigerian scientist, O. Fambitakoye had been trained and therefore been chosen to be the president of the French national committee of the IEEY. O Fambitakoye, A. Onwumechili (Nigeria) and S. Ogunade (Nigeria) coordinated the IEEY project over West Africa.

A network of 10 magnetotelluric stations has been installed and an observatory has been created at Korhogo, in the north of Côte d'Ivoire. In this observatory, an ionosonde, a magnetometer, an interferometer and an HF radar were put into operation. Another HF radar was carried out at Lamto in the south of Ivory Coast, Figure 1 shows the scientific tools of IEEY in West Africa (Amory-Mazaudier et al., 1993).

In this figure, the four ionosondes of Dakar (Senegal), Ouagadougou (Burkina Faso), Ibadan (Nigeria) and Tamanrasset (Algeria) that were operational before the IEEY project are indicated. Some of them, like the one in Dakar had been in operation since 1957 and the one in Ouagadougou, since 1966. The network of magnetotelluric stations provided the three components of the earth's magnetic field $(H, D, Z)$ and the two components of the telluric electric field $E_{x}$ (northward) and $E_{y}$ westward.

At the end of IEEY, in January 1995, the group of scientists who participated in the IEEY formed the GIRGEA (Groupe International de Recherche en Géophysique Europe Afrique) scientific network. The GIRGEA organized a first international school in Abidjan (15-25 October 1995) and 4 young scientists from Côte d'Ivoire had been chosen to perform their theses. The network of magnetotelluric stations which had operated during the 2 years 1992-1994 had been dismantled. The observatory in Korhogo had been maintained with an ionosonde and an interferometer. A network of 3 magnetometers had also been 


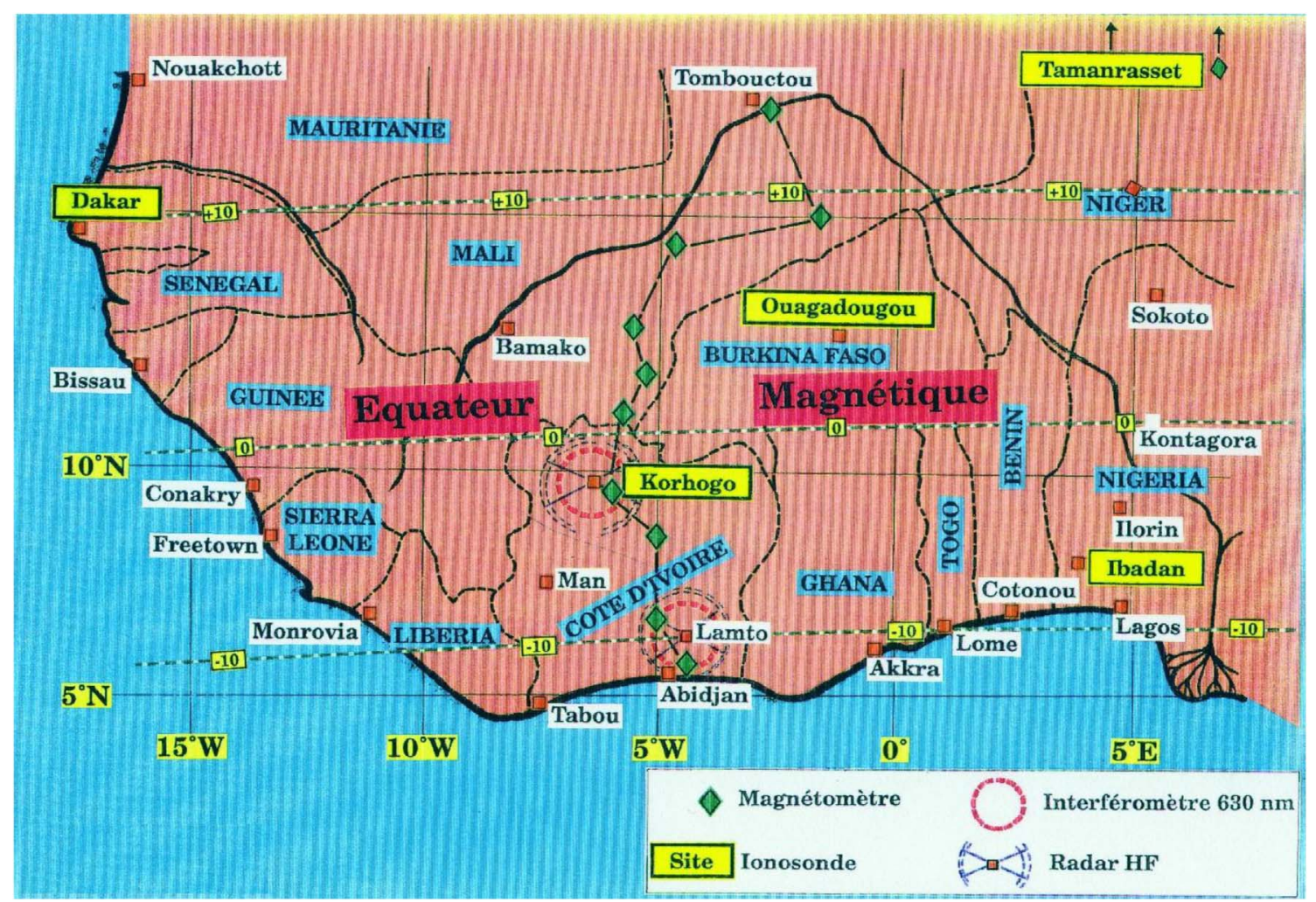

Fig. 1. Scientific tools in West Africa during the IEEY project: in yellow the five ionosondes and in green the chain of ten magnetotelluric stations. Two observatories of Korhogo and Lamto are represented by red circles.

maintained. The Korhogo observatory operated from 1992 to 2002 , the year of the first war in Ivory Coast during which the observatory was destroyed.

In 2005 the members of GIRGEA were contacted by the international community for the IHY project (2007-2009) in Africa. This project gave a second breath to GIRGEA which has developed from 2009 to now schools in various African countries, mostly French-speaking countries. All these schools were developed following a new model for international cooperation tested during IEEY (Amory-Mazaudier, 2002). On the site https://www.girgea.org the reader can find all the reports concerning these different schools.

The IHY project has allowed the implantation of many scientific instruments in the world and more particularly in Africa. This was continued within the framework of the ISWI project. Figure 2 of the site: http://www.iswi-secretariat.org presents these networks of instruments. As part of these projects, scientists installed scientific instruments free of charge in countries without instruments. The IHY and ISWI projects enabled the worldwide system for sharing instruments. GIRGEA which was before IHY and ISWI only active in West Africa (Ivory Coast, Burkina Faso and Senegal) has then extended to other African countries (Algeria, Egypt DRC, RC, Morocco, Tunisia, and Vietnam).

\subsection{GIRGEA schools}

GIRGEA has organized schools in Algeria (2013), Ivory Coast (1995, 2017), DRC (2011), Egypt (2010), Morocco (2010, 2014, 2015), Republic of Congo (2009), Senegal (2019).
The schools aimed:

1. To introduce the students to the Sun-Earth relationships with specialists from different disciplines (physics of the Sun, solar wind, magnetosphere, atmospheric ionosphere and internal and external magnetic field).

2. To analyse the existing data in these different disciplines with digital tools.

3. To develop mini scientific projects on a given event.

4. To learn administration.

5. To promote exchange and cooperation between students of different nationalities.

6. To develop the publication despite the cost sometimes difficult to find.

In these schools, lectures were given in the morning and the afternoon was devoted to practical work.

Regarding the financing of these schools, GIRGEA is a network which does not have a permanent infrastructure and which only runs training schools within the framework of major projects with the help of different laboratories and international structure.

The institutions of the professors participating in the training contribute by covering mobility. The country that organizes the school provides food and accommodation for teachers and students. The teachers have no per diem. Half of the students attending the school are from the host country, and the other half of the students come from countries in the region. The ticket for students is supported by different organizations 


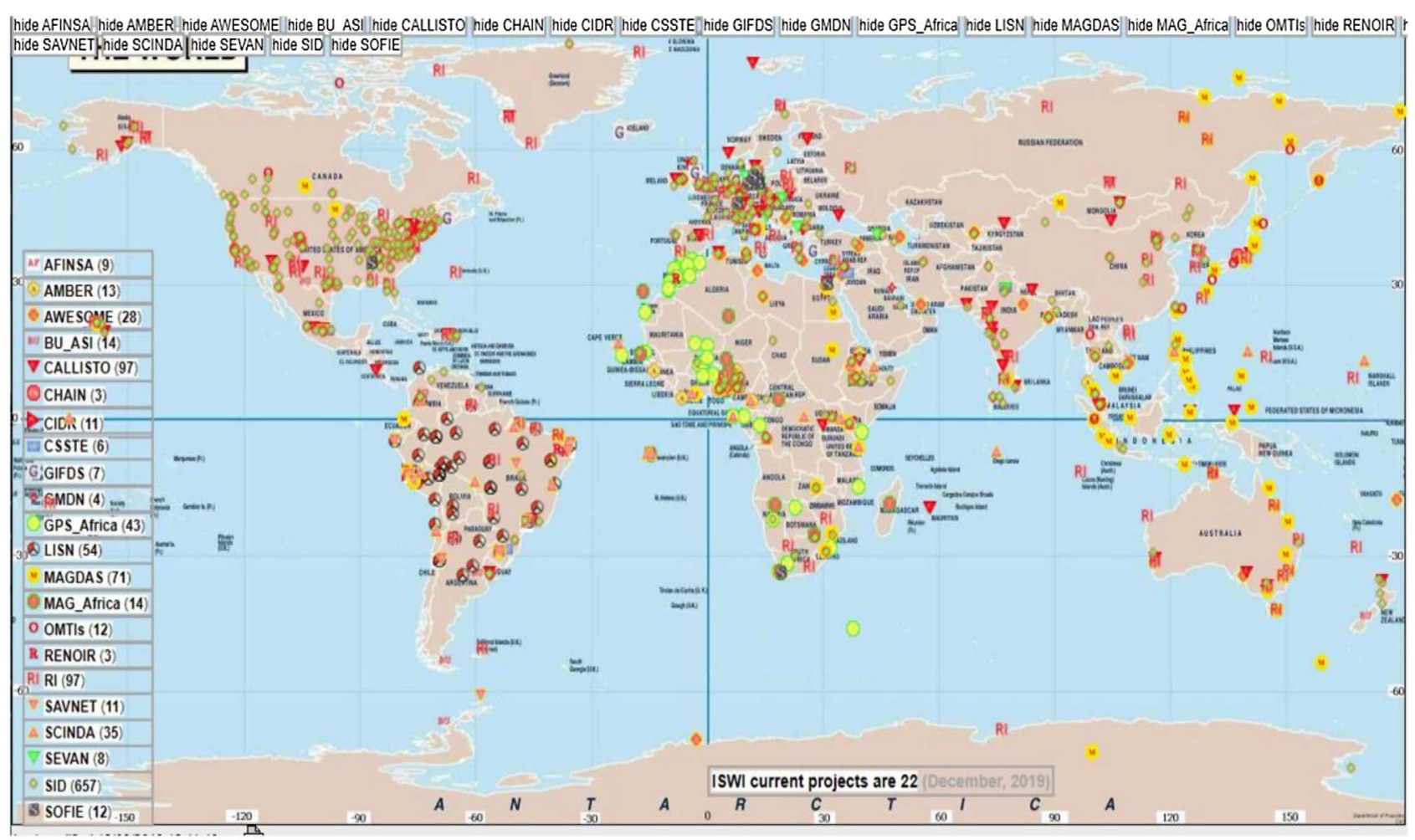

Fig. 2. ISWI instruments, map from http://www.iswi-secretariat.org.

(AUF, French embassies, PNST, CNRS, SCOSTEP, ICTP, MICROSOFT, NASA, EGNOS, and others).

\subsection{GIRGEA - research and results}

Following each school, students selected on criteria of motivation to do research are trained to write a thesis. Then they can access to a position in their country and in turn are able to develop research.

After IHY, the ISWI project (2010-2012) enabled the use of GPS and GNSS data for scientists. These data make it possible to link different scientific communities (seismology, ionosphere, atmosphere, etc, Amory-Mazaudier et al., 2019), and to combine the fundamental physics of Sun-Earth relations to everyday life which is very important for policy makers.

The results of IEEY led to the development of a special issue of Annales Geophysicae in 1998 and a review paper (Amory-Mazaudier et al., 2005). The IEEY experiment reveals the longitudinal variation of the EEJ and the existence of a maximum of the EEJ in Vietnam, therefore studies of GIRGEA were developed in Vietnam.

The IHY project has allowed great advances in understanding the variability of the ionosphere during disturbed magnetic periods, associated to the two components of the solar magnetic field (poloidal and toroidal/sunspot), such as coronal mass ejections or the high speed solar winds flowing from the solar coronal holes. The studies carried out on large databases shown that it is important to study the ascending and descending phases of the sunspot cycle which are asymmetrical, and not to study only the periods of the sunspot maximum or minimum.

The ISWI project highlights the difference between the northern and southern hemisphere.
All the results obtained in GIRGEA from 2005 until 2017 are presented in a review by Amory-Mazaudier et al. (2017).

With the network of GIRGEA scientists, we have trained 56 $\mathrm{PhD}$ students (46 PhD in Africa, in: Algeria, Benin, Burkina Faso, Cameroon, Côte d'Ivoire, DRC, Egypt, Guinea, Conakry, Morocco, Nigeria, RC, Senegal, Tunisia); 43 students have positions in their country and continue their studies, 2 students are waiting for a position and only 1 left his country for personal reasons. University curricula on Sun-Earth connections/space weather have been developed in various universities in African countries (Ivory Coast, Burkina Faso, Algeria, Morocco, DRC, RC, Cameroon, Egypt).

Five scientists from the GIRGEA network (Dr Arsène Kobéa, Dr Vafi Doumbia, Dr Olivier Obrou, Dr Frédéric Ouattara and Dr Jean-Louis Zerbo) have applied for and received Fulbright grants to work with distinguished scientists in USA: Dr Art Richmond, Dr Dieter Bilitza and Dr John Richardson. Table 1 gives more details.

In 2018, Dr. Frédéric Ouattara (from the GIRGEA/Burkina Faso) received the AGU Africa Award for Research Excellence in Space Science for his study connecting the two components of the solar magnetic field to the critical frequency of the ionospheric $F_{2}$ layer.

Contact: Christine Amory-Mazaudier and Rolland Fleury, mail to: christine.amory@lpp.polytechnique. fr, rolland.fleury@imt-atlantique.fr.

\section{4 eGY Africa internet and schools of the GIRGEA}

During the International Union of Geodesy and Geophysics (IUGG) in Toulouse in 2005, the International Heliophysical 
Table 1. Fulbright grants for scientist of the GIRGEA.

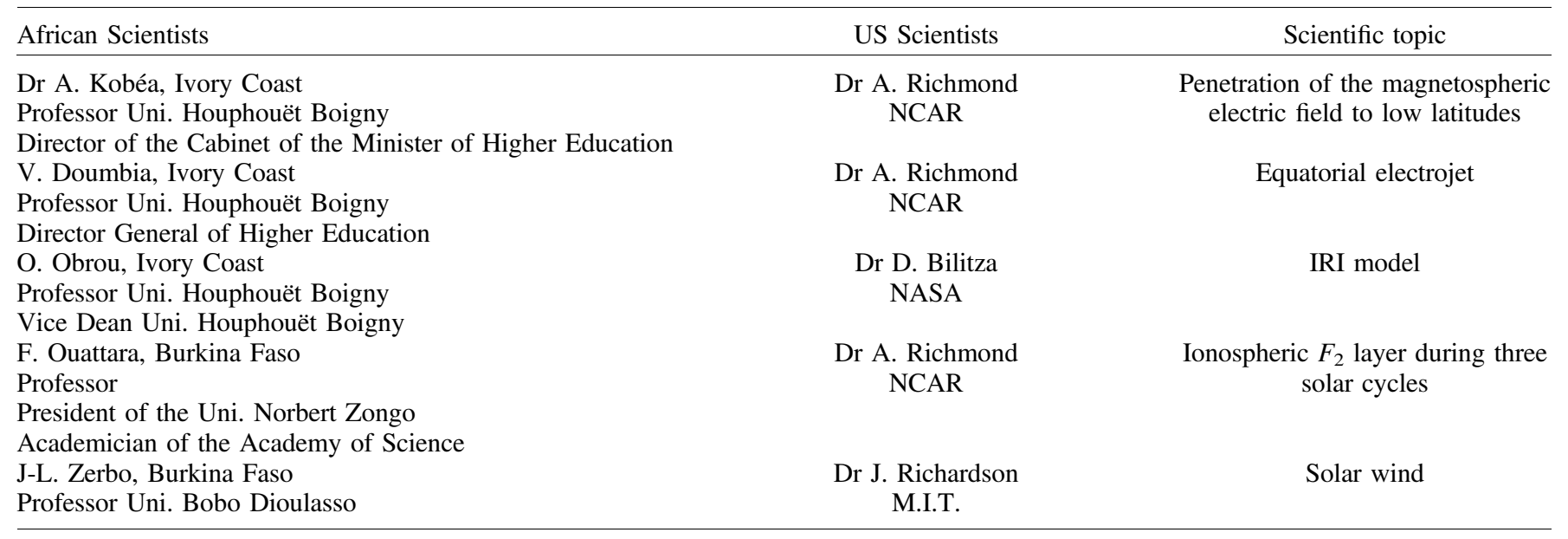

Year (IHY) (2007-2009) was discussed about the participation of African countries, the setting of instruments and the data storage and transmission. One key problem was raised: the Internet status in those African countries will not permit real or delayed time data transfer. C. Barton, president of the IUGG, was made aware about this important issue. For the same reasons, most African countries could not participate to the electronic Geophysical Year (eGY) advanced issues for open data.

eGY-Africa was then initiated as an effort to reduce the Digital Divide in Africa, with cooperation especially from the International Heliophysical Year (IHY) followed by the International Space Weather Initiative (ISWI) community and some other geophysics projects, IUGG being the main sponsor. Many other international programmes and organizations were involved for the improvement of cyberinfrastructure in Africa and several of them like ICSU for Africa, CODATA, Association of African University (AAU) were in contact with eGYAfrica. Reliable and relatively fast networks are the only issue for education and research, international access and collaboration.

The kick-off meeting of eGY-Africa took place during the IHY meeting in 2007 in Ethiopia, with scientists from 19 African countries participating to this meeting. eGY-Africa sought to influence decision-makers and service providers who were in a position to improve institutional Internet capabilities in Africa. Therefore, each year the actual African situation was presented in conferences like eGY in 2009, EGU in 2009, 2010 and 2011, IST-Africa in 2008, 2010 and published in the proceedings of eGY (Barton et al., 2009), of IST-Africa (Barry et al, 2008, 2010).

eGY-Africa meetings were organized in Ethiopia during the IHY meeting in 2007, in Ghana in 2010 and in Kenya in 2012. The number of African countries, participating to those meetings were: 20 in Ethiopia, 5 in Ghana and 10 in Kenya. There were very large differences from one country to another, even in the same geographical area, due to national decision. Then, the implementation of regional Research and Education Networks (REN) has been an important point to improve the situation: since 2009 the UbuntuNet Alliance for Eastern and Southern Africa; then 2011 WACREN for the West and Central Africa and 2011 ASREN for the Arab States.
In the framework of eGY-Africa and, IHY and ISWI, L. Cottrell from SLAC (Standford Laboratory Accelerator) and M. Zhizhin (Space Research Institute (IKI) Russian Academy of Sciences) participated to ISWI Schools and also in the following ways:

- With the help of IHY African partners, L. Cottrell implemented via the PingER project a continuous monitoring of the Internet quality in their university, laboratories and informed them for internet changes in a given country, for example, when some East African countries were connected to a sub-marine cable instead of satellite, or for internet black-out during a period for various reasons. All those information and requirements were used to argue for the need of better internet towards decision-makers and service providers.

- M. Zhizhin provided access to the database "Space Physics Interactive Data Resource (SPIDR)" which was a de facto standard data source for solar-terrestrial physics, functioning within the framework of the World Data Center System. SPIDR permitted to access historical data like magnetic and solar data very useful for some papers and PhDs. This database was unfortunately decommissioned.

In several ISWI schools, in Egypt in 2010, in DRC (Democratic Republic of Congo) in 2011 and in Algeria in 2013, a day was devoted to the scientists, on one hand, to inform them about the status and development plans of cyberinfrastructure and facilities at worldwide, regional, country and even local levels; on the other hand, to ask them to point out in a concrete way their present needs and their dreams relative to their future projects especially at large scale. Scientific teams need e-infrastructure but e-infrastructure is only pertinent if there are committed users. Those meetings had a large impact locally i.e. Egypt, DRC and Algeria, to increase interactions and dialogs among scientists and computer people for present and future applications.

In DRC there was not a master in informatics. Two students participated to this day while presenting their experiment in informatics. For their license memoirs they contacted us and 
could came to France to enroll in master in informatics. One of them is currently a $\mathrm{PhD}$ candidate in this discipline.

Contact: Monique Petitdidier, Ian McHarg Medal, European Geosciences Union, 2011, mail to: monique. petitdidier@latmos.ipsl.fr.

\section{ICTP}

\subsection{ICTP programmes}

ICTP has several programmes to support scientists working in developing countries. Among these have shown to be very effective the Associates and Federated Institutes Programme, and the Sandwich Training Educational Programme (STEP). The Associates Programme enables individual scientists to maintain long term formal contacts with the stimulating and active scientific environment of the Centre through periodic visits to the ICTP. STEP offers fellowships to $\mathrm{PhD}$ students from developing countries in the fields of physics and mathematics through long periodic visit to the Centre. Their thesis work is done under the supervision of a professor of their University and an ICTP researcher.

A good number of scientists working in Ionosphere and Space Weather research particularly in Africa have received Associate or STEP fellowships. Several of them are leading scientists and have been appointed professors and head of department or research unit in African Universities or have received international awards. Recent examples are the following.

Dr. Joseph Olwendo from Kenya, that participated in previous training activities carried out at the Centre, received in 2015 the ICTP Award of Junior Associate and the American Geophysical Union (AGU) "Sunanda and Santimay Basu Early Career Award in Sun-Earth Systems Science” in 2016.

Dr. Melessew Nigussie received his $\mathrm{PhD}$ in space physics from Bahir Dar University, Ethiopia, in 2014, having been awarded in 2011 an ICTP STEP fellowship. In 2017 he received the AGU Africa Award for Research Excellence in Space Science. At present he is the Director of the Washera Geospace and Radar Science Research Laboratory of the Bahir Dar University.

Dr. Andrew Akala from Nigeria, participated in the Workshop on Science Applications of GNSS in Developing Countries in 2012 and was awarded with the Abdus Salam ICTP Associateship from 2015 to 2020. In 2019 he received the AGU Africa Award for Research Excellence in Earth and Space Science.

Dr. Olawale S. Bolaji from Nigeria, participated in the Workshop on Satellite Navigation Science and Technology for Africa in 2009. Later he received the ICTP STEP fellowship and his PhD degree from the University of Ilorin, Nigeria, in 2013.

He has been visiting scientist in research institutions of Australia, Japan, China and USA. In 2020 he received the AGU Africa Award for Research Excellence in Earth and Space Science.

\subsection{ICTP online open-access services}

The ICTP T/ICT4D provides tools and methods that allow researchers to work with different ionospheric datasets. Since 2012 some of these tools were made available via web applications (accessed from https://t-ict4d.ictp.it), with hundred thou-
Table 2. Geographic distribution of the participants attending the ICTP-BC-UNOOSA activities.

\begin{tabular}{lc}
\hline Region & Percentage (\%) \\
\hline Africa & 56 \\
Asia & 17 \\
Europe & 12 \\
Latin America & 10 \\
North America & 2 \\
Oceania & 3 \\
\hline
\end{tabular}

sand of runs per year by users from all regions of the world. The web services include: the NeQuick web model and the GNSS Calibration online.

In the framework of an ICTP Data Sharing Initiative, the T/ ICT4D, in collaboration with the ICTP ICT section, started a project to provide calibrated TEC data from available IGS stations from around the world, plus the continuous flow of almost real time data. The whole available historical dataset is calibrated using the same technique (Ciraolo et al., 2007), making it easy to compare between TEC behaviour in different locations and geographical regions. Ciraolo's technique is referred as the TEC arc-offset method, where the contribution of a given receiver and satellite pair biases and any non-zero averaged errors over an arc of observations, e.g. the multipath, are estimated in a single constant value. The new service looks to automate the routine process of downloading, processing, filtering and plotting the TEC data obtained from GNSS receiver stations, an important resource for developing countries scientists lacking of large computational capacities.

After a beta-test that included a group of scientists from several developing countries who frequently use TEC data to investigate the state of Earth's ionosphere, the new T/ICT4D Calibrated TEC service has been opened to public use during the last "African Workshop on GNSS and Space Weather", held online on 5-6 October 2020, and it is available at: https://t-ict4d. ictp.it/nequick2/gnss-tec-calibration.

\subsection{ICTP-Nepal project}

In the wake of a cooperation initiative started by Prof. Fernando Quevedo, former ICTP Director, after his visit to Nepal, representatives from the Tribhuvan University in Kathmandu and members of the T/ICT4D organized the Workshop on Space Weather and Upper Atmosphere Physics (WSWUAP) with the support of the Office of External Activities of ICTP. The event took place in Kathmandu, Nepal from 23 to 27 September 2019 and brought together 43 participants ( $\mathrm{PhD}$ candidates, MSc and $\mathrm{BSc}$ ) from different parts of the country.

During the workshop the participants received lectures on subjects related to space weather, ionosphere, GNSS and extreme weather events. Hands-on and tutorial sessions allowed the participants to get acquainted to the access and use of space weather data, TEC calibration techniques and ionospheric models. Participants have been engaged in a problem solving experience regarding ionosphere characterization and space weather events reporting their results.

A number of students expressed their interest in continue their studies in space weather and ionosphere. 
This kind of activities is organized in the framework of ICTP's mission and ISWI Education and Training Objective. Yenca Migoya-Orué from ICTP is currently ISWI National Co- Coordinator for Italy.

Contact: Sandro Radicella, Bruno Nava, Yenca Migoya Orue, mail to: rsandro@ictp.it, bnava@ictp.it, yenca@ictp.it.

\section{ICTP-BC}

In December 2006, a "Workshop on the Future of Ionospheric Research for Satellite Navigation and Positioning: Its Relevance for Developing Countries" was organized at the Abdus Salam International Centre for Theoretical Physics (ICTP) in Trieste, Italy. It was directed by Patricia Doherty, from Boston College (BC) in the United States, and Sandro Radicella from the ICTP. The objective was to discuss the opportunity to advance studies on the ionosphere and space weather effects on Global Navigation Satellite System (GNSS) particularly in the near-equatorial regions, where most developing countries lie. GNSS is a space technology with applications and operational systems that can be of great value to developing countries. GNSS applications can be used to increase food security, manage natural resources, provide efficient emergency location services, improve surveying and mapping, and provide greater precision and safety in land, water and air navigation systems. GNSS is also a remarkable tool for ionospheric and space weather studies.

The workshop was quite a success as it was attended by nearly fifty scientists from Africa, Asia, Latin America, Europe and the United States of America. The workshop included scientific presentations; discussions on the importance of facilitating the use of GNSS in developing countries; and the best way forward to achieving that goal. The result of the discussions was a plan to develop periodic training opportunities where state of the art science and applications using GNSS would be made available to researchers, university professors and students of developing countries. It was also recognized that the region that was in most need of such actions was Africa.

Inspired by the success of the 2006 workshop and the apparent need for this technology in Africa, a Memorandum of Understanding (MOU) was signed by ICTP and Boston College (ICTP-BC) in 2009 to form a partnership to conduct training workshops for university lecturers, professors, students and researchers from African countries in the area of ionosphere and space weather research. GNSS would be used widely in the workshops as a tool to study the ionosphere and to also define space weather effects on GNSS technology. The overall objective of the MOU was to create a knowledgeable space weather and GNSS workforce in Africa.

In the same year (2009), the first of a long series of Workshops held in Trieste and in African countries with the participation of international experts and scientists, professors and students from institutions from developing countries mostly from Africa was carried out. It has to be noted that the Institute of Navigation and the United Nations Office of Outer Space Affairs, through the International Committee on GNSS, have supported financially and institutionally these Workshops from the start.
The workshops have continued almost annually with 10 activities carried out at ICTP in Trieste, Italy and one in Kigali, Rwanda. The workshops have been attended by approximately 432 participants (29\% female, $71 \%$ male). As can be seen from Table 2, indicating the geographic distribution of the participants, the majority of the attendees were from Africa. It is also to be noted that each year, more and more participants were women. In fact, $50 \%$ of the participants in the Workshop carried out in 2017, were women.

The most recent workshop was to be held in Morocco in October 2020. Due to travel restrictions related to Covid-19, the workshop was held virtually on 5 and 6 October. This virtual workshop was attended by 150 participants, mostly from Africa and Asia. The level of interest in the virtual workshop reinforces that the periodic workshops continue to provide a valuable service to scientists and students in developing countries.

There have been many positive impacts of the ICTP-BC partnership training activities on the advancement of ionosphere and space weather science in Africa. The best evidence is the increase in the number of scientific papers produced by African scientists in the specific area of ionosphere research. Figure 3 shows the percentage of the total number of papers published on "equatorial ionosphere" by African scientists (first Author working in Africa). The source used was the Web of Science Core Collection.

From 2010 to May 2019 (the last month considered in the figure that corresponds to the month of the last Workshop carried out in person under the partnership) $86 \%$ of the papers were written by African scientists that participated in the partnership training activities or in ICTP programmes like Associates and STEP. The increase of the percentage from the biennium 2010 to 2011 on (after the initial partnership activity) is manifest and indicates the impact of the periodic training activities done under the ICTP-BC partnership.

The workshops will continue in the future with the next workshop planned to be held at the CRASTE-LF (Centre Régional Africain des Sciences et Technologies de l'Espace en Langue Française affilié I'ONU) in October 2021.

Contact: Sandro Radicella, Patricia Doherty, Bruno Nava, mail to: rsandro@ictp. it, patricia.doherty@bc. edu, bnava@ictp.it.

\section{United Nations Office for Outer Space Affairs: ICG and CRASTE-LF}

\subsection{International Committee on Global Navigation Satellite Systems}

The International Committee on Global Navigation Satellite Systems (ICG) is an innovative international coordinating committee designed to encourage interoperability and compatibility of satellite navigation systems and to promote GNSS in developing world. The ICG also aims to foster science and technology education about GNSS application in the developed and developing nations. Currently, the work of the ICG is being supported by UNOOSA, which has served as the Executive Secretariat for matters relating to organizing the ICG meetings since its establishment in 2005 . The ICG meets regularly to address issues of common interest focusing on systems, signals 


\section{$\%$ of the Total number of papers published on \\ "equatorial ionosphere" by African scientists (first author African working in Africa) (source Web of Science Core Collection)}

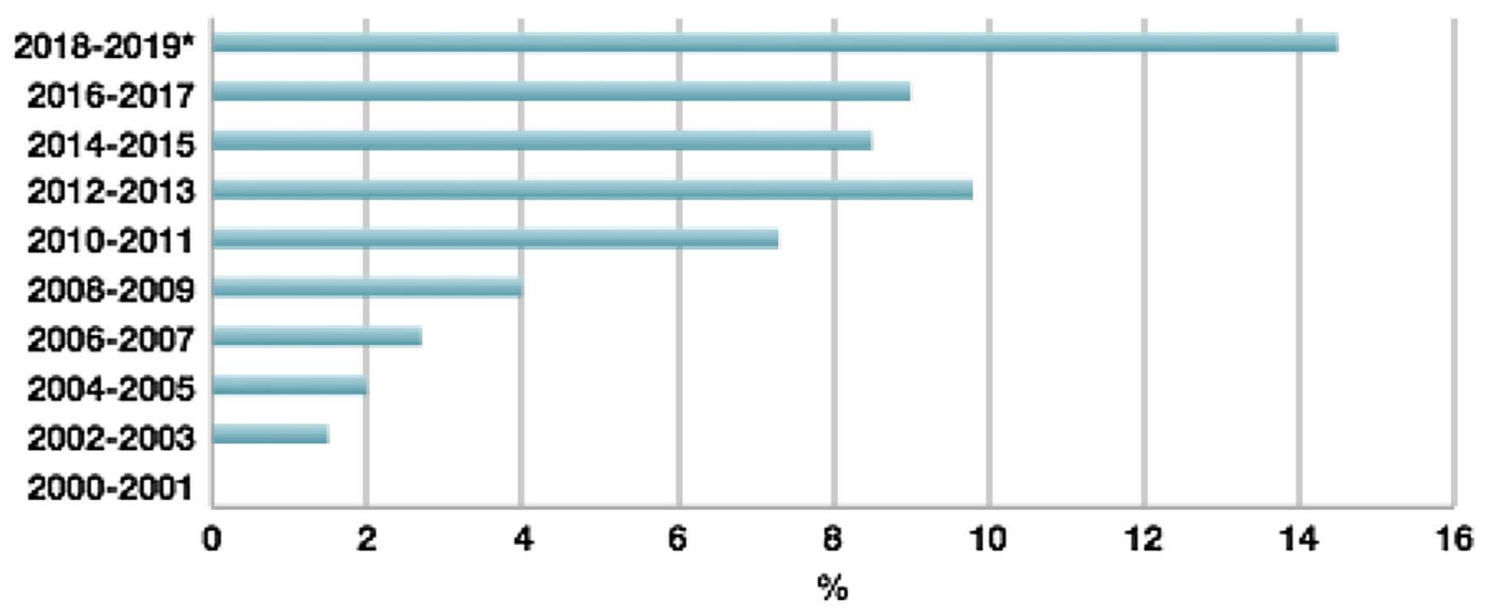

Fig. 3. Percentage of papers published by African scientists from Web of Science Core Collection.

and services; enhancement of GNSS performance, new services and capabilities; information dissemination and capacitybuilding; and reference frames, timing and applications. UNOOSA will host and chair the 15th meeting of ICG on 27 September - 1 October 2021 in Vienna.

The activities and opportunities provided through the ICG programme on GNSS applications and implemented by UNOOSA result in the development and growth of capacities that will enable each country to enhance its knowledge, understanding and practical experience in those aspects of GNSS technology that have the potential for greater impact on its economic and social development, including the preservation of the environment.

\subsection{UNOOSA}

To focus on GNSS-based technology and the threat of space weather on GNSS systems and application since 2006 UNOOSA organizes a series of the workshops on GNSS that bring together a large number of experts to discuss and act on issues that are also of high relevance to ICG. The overall objective of these workshops is to define the needs and requirements of end-users of GNSS and to provide a framework for scientific research enabled by GNSS. The programme of the workshops is aimed at contributing to the creation of a knowledgeable workforce, necessary for the advancement of science applications of GNSS in the regions (United Nations, 2019).

Efforts to build capacity in space science and technology are considered a major focus of UNOOSA and, thus, provide a major springboard for the transfer and enhancement of skills and knowledge to nations that wished to engage in GNSS science, technology and education.

The Regional Centres for Space Science and Technology Education, that are affiliated with the United Nations through an agreement with UNOOSA, are located in Morocco and Nigeria for Africa, in India and China for Asia and the Pacific, in
Brazil and Mexico for Latin America and the Caribbean, and in Jordan for Western Asia. The centres, also acting as information centres for ICG, use existing facilities and expertise already available in education and other research institutions in their respective regions to conduct short- and long-term training courses on various aspects of GNSS. The centres develop courses on GNSS that are followed by young professionals and educators from the countries in their regions. By so doing, the centres foster the development of contacts among countries and the initiation of new research, thereby facilitating the development of GNSS-related applications (Gadimova and Haubold, 2009; United Nations, 2012).

Contact: Sharafat Gadimova, mail to: sharafat. gadimova@unoosa.org.

\subsection{CRASTE-LF}

The CRASTE-LF (https://crastelf.org.ma, Centre Regional Africain des Sciences et Technologies de 1'Espace en Langue Francaise/African Regional Centre for Space Science and Technology Education - in French Language) was established in Morocco on 23 October 1998 under the auspice of UNOOSA and endorsed by the United Nations General Assembly Resolution - 45/72 of 11 November 1990 and - 50/27 of 6 December 1995.

The CRASTE-LF is based at the Mohammadia School of Engineers of the Mohammed V University of Rabat. It was initially founded by 11 Member States, including Algeria, Cameroon, Cape Verde, Central African Republic, DR Congo, Gabon, Morocco, Mauritania, Niger, Togo and Tunisia, and subsequently joined by Senegal in 2002 and Côte d'Ivoire in 2004. The Centre objectives are:

- To increase knowledge in Space Sciences and Technologies by organizing Postgraduate and/or Short courses, Seminars, Workshops, Conferences at a regional level. 
- To improve the technical competences of the experts, teachers, decision-makers and to hold them informed about technical progress and to hold them informed about technical progress.

- To assist the countries of the region on the development of endogens capacities in space tools.

- To Strengthen the Local and Regional Capacities.

- To promote Cooperation between the Developed Countries and States Members as well as among these States.

- To develop expertise in Space Sciences and Technology.

- Provide advisory services to Member States and regional institutions that have made the request.

- Collect and disseminate information related to space and space technologies.

Each year, CRASTE-LF organizes post-graduate level courses in a Master in Space Science and Technology. So far 30 courses were conducted for 444 trainees from 22 member and non-member countries of CRASTE-LF. Additionally, 15 sessions were organized in Remote Sensing \& Geographic Information System (GIS) for 282 trainees, 7 sessions in Satellite Meteorology \& Global Climate for 70 trainees and 3 sessions in Satellite Communications for 38 trainees. The number of trainees that participated in CRASTE-LF courses each year since 2000 is given in Figure 4 below, including their country of origin.

In 2013, CRASTE-LF created a Master in GNSS. From 2016, the Master's degree programme is accredited in partnership with the Agronomic and Veterinary Institute Hassan II of Morocco. Since 2013 CRASTE-LF has organized 5 sessions in GNSS for the benefit of 54 trainees.

CRASTE-LF also has conducted several short courses, seminars, workshops and conferences in Space Science and Technology. Between 2010 and 2020, there were organized 54 activities in all disciplines of Space Science and Technology, including 12 GNSS activities, for the benefit of almost 3,000 African executives.

Thus, in view of the latest developments in space technologies and their use for societal benefits, CRASTE-LF as all the United Nations - affiliated Regional Centres for Space Science and Technology Education, takes a considerable effort at the capacity-building in the field of space technologies, including GNSS.

Contact: Anas Emran, mail to: craste@emi.ac.ma.

\section{SCOSTEP}

The Scientific Committee on Solar-Terrestrial Physics (SCOSTEP) is a Thematic Organization of the International Science Council (ISC). SCOSTEP has run long-term international interdisciplinary scientific programmes on solar-terrestrial physics since 1966. These programmes include Climate and Weather of the Sun-Earth System (CAWSES-I/-II, 20042013, Tsuda et al., 2015), Variability of the Sun and its Terrestrial Impact (VarSITI, 2014-2018, Shiokawa \& Georgieva, 2021), and the newest programme: Predictability of the Variable Solar-Terrestrial Coupling (PRESTO, 2020-2024). CAWSES-I and -II focused on solar influence on climate changes, effects of sporadic solar events on the terrestrial system and satellite missions in near-Earth orbit, and the coupling of atmospheric layers through dynamical, electromagnetic, and photo-chemical processes. VarSITI mainly focused on the declining solar activities including possible solar grand minimum and their impact on the Earth's environment for both short- and long-term variabilities with their consequences on human life. The new programme, PRESTO, intends to improve the predictability of energy flow in the integrated Sun-Earth system on times scales from a few hours to centuries through promoting international collaborative efforts. SCOSTEP also interacts with national and international programmes involving solar terrestrial physics elements. One of the major tasks of SCOSTEP is the capacity building of solar-terrestrial physics for young scientists and students. All these SCOSTEP activities are summarized at https://scostep.org/. The following describes past and planned SCOSTEP activities that support capacity building.

International Space Science Schools and Workshops: SCOSTEP partners with other international bodies, such as the International Space Weather Initiative (ISWI), to train university students to become next generation scientists via International Space Science Schools and Workshops consisting of lectures and hands-on activities.

Examples of events held in collaboration with ISWI are shown in Table 3, such as the school held in Nairobi Kenya on October 21-November 1, 2013.

SCOSTEP/VarSITI Schools and Database: The recent SCOSTEP/VarSITI programme (2014-2018) has also organized five schools in Indonesia, Nigeria, and Russia (Shiokawa $\&$ Georgieva, 2021) as shown in Table 3. There were two schools in Nigeria, namely the International School on Equatorial and Low-Latitude Ionosphere (ISELLI) and ISELLI-2. Other two schools were also held in Bandung, Indonesia named International School on Equatorial and Low-Latitude Ionosphere (ISELION) and ISELION2018. The school in Russia was held on July 9-12, 2017 in Irkutsk, Russia, in association with the VarSITI 2017 General Symposium (July 10-15, 2017) at the same venue. VarSITI also compiled a list of databases and data analysis tools of solar-terrestrial physics, particularly for use of young scientists and students in developing countries. The database list is available at http://www.varsiti.org/.

SCOSTEP Visiting Scholar (SVS) Programme: Since 2015, SCOSTEP has been operating the SVS programme every year. The SVS programme is to provide training to young scientists and graduate students from developing countries in wellestablished solar-terrestrial physics laboratories, for periods of between one and three months. The training helps the young scientists to advance their career in solar-terrestrial physics using the techniques and skills they learned during the training. SCOSTEP provides the airfare, while the host laboratory provides the living expenses. SCOSTEP has funded 4-9 scholars every year from various developing countries since 2015. Currently, more than 10 laboratories in the world are registered as hosts of the SVS programme. Some young scientists who joined the SVS programme have already been assigned in academic positions in their home countries. The past SVS participants, host institutions, and announcement of application are available at https://scostep.org/svs/.

SCOSTEP Online Capacity Building Lecture Series: During the pandemic situation of COVID-19, SCOSTEP has recently introduced an online Capacity Building Lecture Series. 


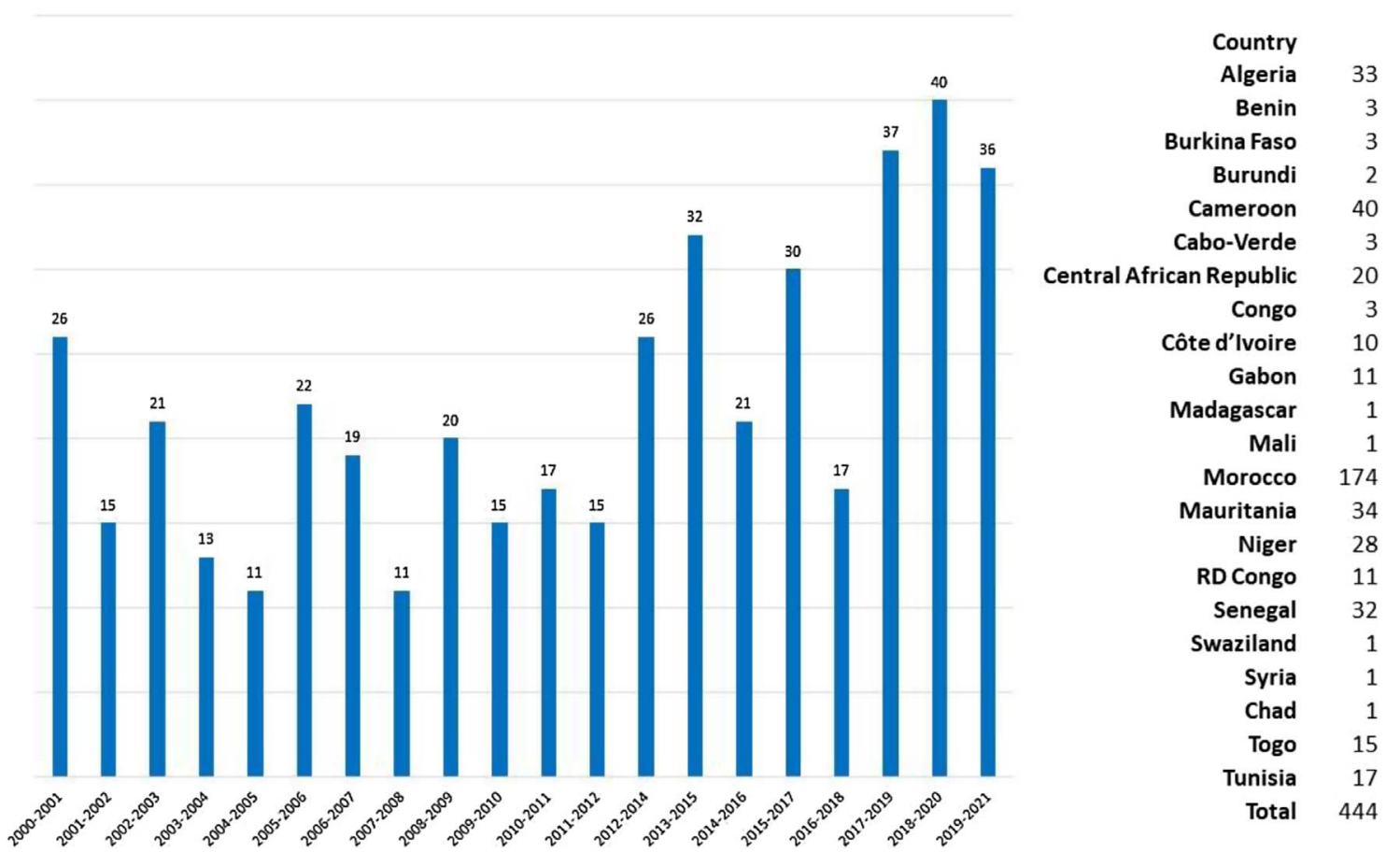

Fig. 4. Number of trainees participating in CRASTE-LF courses per year and per country since 2000.

Table 3. Examples of capacity building schools organized by SCOSTEP.

\begin{tabular}{|c|c|c|c|c|}
\hline Place & Dates & Initiatives & Participants and countries & $\begin{array}{l}\text { Additional outreach to } \\
\text { younger students and kids }\end{array}$ \\
\hline Nairobi, Kenya & $\begin{array}{c}\text { October } 21- \\
\text { November } 1,2003\end{array}$ & SCOSTEP and ISWI & $\begin{array}{l}39 \text { students from } 7 \\
\text { countries }\end{array}$ & $\begin{array}{l}\text { High school students from the } \\
\text { backhouse in Nairobi visited where the } \\
\text { students learned about space situational } \\
\text { awareness and space weather. }\end{array}$ \\
\hline Lima, Peru & $\begin{array}{c}\text { September } 15-24 \text {, } \\
2014\end{array}$ & SCOSTEP and ISWI & $\begin{array}{c}42 \text { students from } 9 \\
\text { countries }\end{array}$ & \\
\hline Abuja, Nigeria & $\begin{array}{c}\text { September } 14-18 \text {, } \\
2015\end{array}$ & $\begin{array}{l}\text { SCOSTEP's VarSITI } \\
\text { program }\end{array}$ & $\begin{array}{c}65 \text { students from } 7 \text { African } \\
\text { countries }\end{array}$ & $\begin{array}{c}\text { An outreach seminar was made at a } \\
\text { local elementary/junior high school in } \\
\text { Abuja. }\end{array}$ \\
\hline $\begin{array}{l}\text { Sangli } \\
\text { Maharastra, } \\
\text { India }\end{array}$ & $\begin{array}{c}\text { November 7-17, } \\
2016\end{array}$ & SCOSTEP and ISWI & $\begin{array}{l}74 \text { students from } 14 \\
\text { countries }\end{array}$ & $\begin{array}{l}\text { A Question/Answer session was } \\
\text { included with } \sim 100 \text { science students } \\
\text { from local Sangli high schools. }\end{array}$ \\
\hline $\begin{array}{l}\text { Bandung, } \\
\text { Indonesia }\end{array}$ & March 5-9, 2018 & $\begin{array}{l}\text { SCOSTEP's VarSITI } \\
\text { program }\end{array}$ & $\begin{array}{c}40 \text { students from } 7 \text { Asian } \\
\text { countries }\end{array}$ & \\
\hline $\begin{array}{l}\text { Baku, } \\
\text { Azerbaijan }\end{array}$ & October 8-12, 2018 & SCOSTEP and ISWI & $\begin{array}{l}53 \text { students from } 24 \\
\text { countries }\end{array}$ & \\
\hline
\end{tabular}

These online lectures will provide both basic background and introductions to the latest scientific topics of solar-terrestrial physics to students and young scientists of all countries. The first speaker of the lecture was Dr. David G. Sibeck of NASA Goddard Space Flight Center about the soft X-ray imaging and plans for the STORM global imaging mission. More lectures by representative scientists in the field of solar-terrestrial physics will follow. Information on this lecture series is available on the SCOSTEP website (https://www.scostep.org).

SCOSTEP Capacity Building School and Workshop Grants: Not only organizing international schools and online lectures as above, SCOSTEP also provides grants for school organizers for capacity building of students and young scientists in solar-terrestrial physics. These grants can be used to facilitate 
travel expenses, visa costs, accommodation and per diem of selected participants, registration fee waivers, and costs for online schools. SCOSTEP further supports the schools by endorsing lecturers for the school from the SCOSTEP Science Disciplinary Representatives, National Adherents and other SCOSTEP-related officers. For more details, see the SCOSTEP website or contact the Scientific Secretary (scostep at https:// www.bc.edu/).

SCOSTEP Comic books: SCOSTEP distributes comic books designed to introduce the public, particularly young people, to several topics in Solar-Terrestrial Physics. The comic books were originally written by Hayanon (https://www. hayanon.jp) with coordination by Prof. Yosuke Kamide at the Solar-Terrestrial Energy Laboratory (currently Institute for Space-Earth Environmental Research) of Nagoya University in Japan, in collaboration with the SCOSTEP's CAWSES programme. Since then, the comic books have been translated into English and French, and several are available in Czech, German, Hindi, Italian, Japanese, Korean, Russian, Spanish, Tamil, and Urdu. These comic books are accessible at the SCOSTEP website: https://scostep.org/.

In summary, SCOSTEP has been engaged in science, capacity building, and public outreach to develop and sustain interest in Sun-Earth connections. SCOSTEP has also promoted efficient exchange of data and information between solar and terrestrial scientists in all countries. Finally, SCOSTEP seeks projects and programmes that cross over traditional boundaries of physical regions and focused scientific disciplines.

Contact: Kazuo Shiokawa, Patricia Doherty, mail to: shiokawa@nagoya-up.jp, patricia.doherty@bc. edu.

\section{Conclusion}

In this article we have presented the actions of 6 different structures (scientific network GIRGEA, ICTP, Boston College, ICG, CRASTE-LF and SCOSTEP scientific organizations) which worked in synergy for the development of research capacities in Africa. This success is also the result of work carried out by scientists during 3 major international projects IEEY, IHY and ISWI falling within the framework of a United Nations BSSI. Many scientists have prepared the ground by bringing their skills and also instruments to Africa (http:// www.iswi-secretariat.org). This development in capacity building began 3 decades ago and many political events took place in Africa during these 3 decades: 2 wars in Ivory Coast (2002 and 2011), the revolution in Egypt and North African countries / Arab Spring (2010), the military coup in Burkina Faso (2015) and riots in some countries ( $\mathrm{RC}, \mathrm{DRC})$ during the elections. Despite all these events the research continued. Humans have played a key role: many students interested in the scientific field (and therefore ours in training courses and international meetings) and therefore it is necessary to further increase cooperation, supervision to break an existing isolation.

Today more than half of the African countries among the 54 have developed research in space science and applications, including space weather studies. African researchers of international standing in these countries organize workshops and training in universities.
GIRGEA has organized a regional network bringing together many French-speaking countries and now every 2 years, since 2013, an IMAO school (ISWI Maghreb West Africa) takes place in one of the countries of the network. This made it possible to develop research on a regional scale, by bringing together small countries. Since 2009, through joint training activities including hands-on sessions, the ICTP and Boston College have contributed to the development of a solid workforce at African university level in the field. ICTP have supported the advancement of space science in Africa and other regions through programmes like the Associate scheme and STEP.

The ICTP-BC workshops in cooperation with the ICG will continue in the future with the next workshop planned to be held at the United Nations affiliated CRASTE-LF in October 2021.

SCOSTEP has initiated their newest long-term scientific programme: Predictability of the Variable Solar-Terrestrial Coupling (PRESTO) programme to perform in the years 2020 2024. SCOSTEP will also continue to organize capacity-building schools in collaboration with ISWI, UN/COPUOS; provide grants to support capacity building activities in solar-terrestrial physics; and continue the SVS programme inviting students in developing countries to well-established laboratories. Finally, SCOSTEP has begun a new series of online capacity building lectures.

CRASTE-LF, continues its training action in Africa through post-graduate training focused on a GNSS Master's degree in French, unique in the world, and short-courses to develop and strengthen African institutions skills.

The activities and opportunities provided through the ICG result in the development and growth of capacities that will enable each country to enhance its knowledge, understanding and practical experience in those aspects of GNSS technology that have the potential for a greater impact on its economic and social development, including the preservation of its environment.

It is still necessary to increase the installation of equipment given the specificity of the equatorial zone despite political instabilities (vast inaccessible regions) and also electrical supply problems which are the current reality.

Many International, Regional and/or local Information and Communication Technology (ICT) projects in Africa were, have been and are running to improve the Internet and all related services. However, as it was initiated by eGY-Africa, it is still important to continue (1) following-up the development and reliability of regional and local communication networks and services, (2) updating the requirements of the Space Science field, and (3) making aware regional and local REN about the present and future Space Science needs.

Acknowledgements. All the authors thank the scientists who participated in the various scientific projects and particularly those who distributed instruments, see http://www.iswi-secretariat.org. The GIRGEA is grateful to all the sponsors of its schools: AUF, French embassies, PNST, CNRS, SCOSTEP, ICTP, MICROSOFT, NASA, EGNOS. The ICTP and BC are grateful to all of the participants and lecturers who have committed their time to this successful venture. The ICG sponsorship of the outreach workshops and training courses and the participation of its members are sincerely appreciated. 
The editor thanks Idrissa Gaye for his assistance in evaluating this paper.

\section{References}

Amory-Mazaudier C, Achache J, Achy-Seka A, Albouy Y, Blanc E, et al. 1993. International Equatorial Electrojet Year. Braz $J$ Geophys 11(3): 303-317. Special issue, invited paper.

Amory-Mazaudier C. 2002. Ideas and research programmes, Earth's environment international cooperation. In: Book of history of geomagnetism and aeronomy, solar variability and geomagnetism, Schroeder W (Ed.), Science edition AKGGKP, Bremen-Ronnebeck, Postdam. ISSN 1615-2824.

Amory-Mazaudier C, Kobea A, Vila P, Achy-Seka A, Blanc E, et al. 2005. On equatorial geophysics studies: The IGRGEA results during the last decade. J Atmos Sol-Terr Phys 67(4): 301-313. https://doi.org/10.1016/j.jastp.2004.10.001.

Amory-Mazaudier C, Fleury R, Petitdidier M, Soula S, Masson F, et al. 2017. Recent advances in atmospheric, solar-terrestrial physics and space weather, from a north-south network of scientists [2006-2016], part B: Results and capacity building. Sun Geosph 2(Supplement): 21-69. ISSN 2367-8852.

Amory-Mazaudier C, Fleury R, Masson F, Gadimova S, Anas E. 2019. Training on GNSS and space weather in Africa in the framework of a north-south scientific network GIRGEA. Sun Geosph 14(1): 71-79. https://doi.org/10.31401/SunGeo.2019.01.10.

Barry B, Chukwuma V, Petitdidier M, Cottrell L, Barton C. 2008. Digital divide in Sub-Saharan Africa Universities: Recommendations and monitoring. In: IST-Africa 2008 Conference Proceedings, 2008, Cunningham $\mathrm{P}$, Cunningham M (Eds.), IIMC International Information Management Corporation. ISBN: 9781-905824-07-6.

Barry B, Barton C, Chukwuma V, Cottrell L, Kalim U, Petitdidier M, Rabiu B. 2010. eGY-Africa: Better internet connectivity to reduce the digital divide. In: IST-Africa 2010 Conference Proceedings, Cunningham P, Cunningham M (Eds.), IIMC International Information Management Corporation. ISBN: 978-1-905824-15-1.

Barton CE, Amory-Mazaudier C, Barry B, Chukwuma V, Cottrell RL, Kalim U, Mebrahtu A, Petitdidier M, Rabiu B, Reeves C.
2009. eGY-Africa: Addressing the digital divide for science in Africa. In: Proceedings of the Electronic Geophysical Year: State of the arts and results, 3-6 June 2009, Pereslavl-Zalessky, Russia, Russian Journal of Earth Sciences, Vol. 11, ES1003 p. https://doi. org/10.2205/2009ES000377.

Ciraolo L, Azpilicueta F, Brunini C, Meza A, Radicella SM. 2007. Calibration errors on experimental slant total electron content (TEC) determined with GPS. Journal of Geodesy 81: 111-120. https://doi.org/10.1007/s00190-006-0093-1.

Davila J, Gopalswamy N, Haubold HJ, Thompson B. 2007. International Heliophysical Year 2007: Basic space science initiatives, science direct. Space Policy 23: 121-126. https://doi. org/10.1016/j.spacepol.2007.02.015.

Gadimova S, Haubold HJ. 2009. Regional centres for space science and technology education and ICG information centres affiliated to the United Nations. Adv Space Res 43(12): 1863-1865. https://doi. org/10.1016/j.asr.2008.12.014.

Harrison R, Breen A, Bromage B, Davila J. 2005. 2007: International Heliophysical Year. Astron Geophys 46: 3.27-3.30. https://doi. org/10.1111/j.1468-4004.2005.46327.x.

Haubold HJ, Gadimova S. 2010. Progress in basic space science education and research: The UNBSSI. Space Policy 26(1): 61-63.

Kitamura M, Wentzel D, Henden AA, Bennett J, Al Naimiy HMK, et al. 2006. The United Nations Basic Science Initiative: the TRIPOD concept. In: Proceedings IAU symposium, International Astronomical Union.

Shiokawa K, Georgieva K. 2021. A review of the SCOSTEP's 5-year scientific program VarSITI - Variability of the sun and its terrestrial impact. Progr Earth Planet Sci 8. https://doi.org/ 10.1186/s40645-021-00410-1.

Tsuda T, Shepherd M, Gopalswamy N. 2015. Advancing the understanding of the Sun-Earth interaction - The Climate and Weather of the Sun-Earth System (CAWSES) II program. Progr Earth Planet Sci 2(1): 28. https://doi.org/10.1186/s40645-0150059-0.

United Nations. 2012. Education curriculum on global navigation satellite systems, ST/SPACE/59, Vienna.

United Nations. 2019. Activities carried out in 2019 in the framework of the workplan of the International Committee on Global Navigation Satellite Systems, A/AC.105/1213, Vienna.

Cite this article as: Amory-Mazaudier C, Radicella S, Doherty P, Gadimova S, Fleury R, et al. 2021. Development of research capacities in space weather: a successful international cooperation. J. Space Weather Space Clim. 11, 28. https://doi.org/10.1051/swsc/2021006. 